М. Б. Матанцеева. Практическая лексикография как одно из направлений работы кафедры русского языка и общего языкознания

Научная статья

УДК 81 '374

DOI 10.18101/2686-7095-2021-3-65-71

\title{
ПРАКТИЧЕСКАЯ ЛЕКСИКОГРАФИЯ \\ КАК ОДНО ИЗ НАПРАВЛЕНИЙ РАБОТЫ КАФЕДРЫ РУССКОГО ЯЗЫКА И ОБЩЕГО ЯЗЫКОЗНАНИЯ
}

\author{
(C) Матанцева Марина Борисовна \\ кандидат филологических наук, доцент \\ кафедры русского языка и общего языкознания, \\ Бурятский государственный университет им. Доржи Банзарова \\ Россия, 670000, г. Улан-Удэ, ул. Ранжурова, 6 \\ m_matantseva@mail.ru
}

\begin{abstract}
Аннотация. В 2019 г. исполнилось 20 лет с момента выхода «Словаря говоров старообрядцев (семейских) Забайкалья». К этой дате приурочено проведение всероссийской конференции «Вопросы региональной, современной и исторической лексикографии и лексикологии», организованной кафедрой русского языка и общего языкознания Бурятского государственного университета им. Доржи Банзарова. В статье предлагается обзор основных лексикографических трудов преподавателей данной кафедры. В их числе «Бурятско-русский и русско-бурятский словарь», «Словарь говоров старообрядцев (семейских) Забайкалья», лексикографическое описание «Экспрессивная лексики говоров старообрядцев Забайкалья», «Словарь русского языка XVIII в.: Восточная Сибирь. Забайкалье» - работы, ставшие заметным явлением в региональной и сибирской лексикографии. Обозначены новые задачи и перспективы словарной работы.

Ключевые слова: практическая лексикография, юбилей словаря, лексикографические труды, переводной двуязычный словарь, диалектный словарь, региональный исторический словарь, аспектный словарь, словарь экспрессивной лексики, словарные проекты, хрестоматия.
\end{abstract}

\section{Для цитирования}

Матанцева М. Б. Практическая лексикография как одно из направлений работы кафедры русского языка и общего языкознания // Вестник Бурятского государственного университета. Филология. 2021. Вып. 3. С. 65-71.

В 2019 г. исполнилось 20 лет с момента выхода «Словаря говоров старообрядцев (семейских) Забайкалья» (далее СГССЗ). Запланированная к этой дате конференция по вопросам лексикографии в связи с трудностями, вызванными сложной эпидемиологической ситуацией, изменением и перестройкой форматов преподавания и научного общения в результате проводится несколько позже, в 2021 г., но с не меньшей степенью интереса к заявленной проблематике.

Инициатором проведения конференции выступила кафедра русского языка и общего языкознания, ранее кафедра русского языка, которая существует с первого дня открытия нашего вуза и сейчас входит в состав отечественного отделения Института филологии, иностранных языков и массовых коммуникаций, одного из самых крупных подразделений Бурятского государственного университета им. Доржи Банзарова. 
За более чем 20 лет, прошедшие с момента публикации СГССЗ, вышли различные лексикографические труды преподавателей кафедры. Практика составления словарей существовала и до выхода этого словаря. Хотелось бы осмыслить некоторые результаты этого направления деятельности кафедры и обозначить перспективы, стоящие перед нами на данном этапе.

На протяжении 90-летней истории существования кафедры (в 2022 г. БГПИБГУ отметит свой 90-летний юбилей) коллектив работал над многими научными задачами. Поскольку до 1996 г. вуз готовил педагогические кадры для Республики Бурятия, основными научными направлениями кафедры русского языка долгое время были прежде всего методика преподавания русского языка в русской и бурятской школах, различные проблемы русско-бурятского и бурятско-русского двуязычия (в 1980-90-е гг. руководители научных направлений О. Д. Бухаева и С. М. Бабушкин). Много внимания было уделено вопросам сопоставительной фонетики и грамматики, преподавания русского языка в вузе. Сложилась в тот же период и успешно работает научная школа О. А. Нечаевой, занимающаяся проблемами функционально-смысловых типов речи. Активно исследовался региональный материал: это язык произведений писателей Сибири (под руководством О. А. Нечаевой), русские говоры Забайкалья (под руководством Е. И. Тынтуевой, Т. Б. Юмсуновой).

С переходом на университетские образовательные программы, реорганизацией структуры факультета/института, пополнением кадрового состава кафедры перечень научных интересов кафедры существенно расширился. В 2000-е гг. коллектив успешно работает над проблемами исторического лингвокраеведения (под руководством А. П. Майорова), языковой картины мира Байкальского региона (под руководством В. М. Егодуровой).

Сегодня преподаватели продолжают трудиться в соответствии с требованиями времени и научным потенциалом преподавателей в рамках трех научных направлений: сопоставительно-типологические исследования разноструктурных языков (научный руководитель д-р филол. наук, доц. Е. А. Бардамова); региональный вариант национального языка Забайкалья: история и современное состояние (научные руководители д-р филол. наук, проф. А. П. Майоров, д-р филол. наук, доц. Д. Ш. Харанутова); функционально-смысловые типы речи (научный руководитель канд. филол. наук, доц. Л. Н. Омельченко). Все направления работы имеют значительные научные результаты в виде статей, монографий, кандидатских и докторских диссертаций.

Решение ряда научных задач завершилось публикацией словарей. Успехом и закономерным результатом работы над проблемами бурятско-русского двуязычия явился двуязычный переводной «Бурятско-русский словарь», изданный в 1992 г. Автор издания С. М. Бабушкин, д-р пед. наук, профессор кафедры русского языка. В предисловии к изданию указывается, что Словарь возник из потребности понимать тексты на неродном языке, в данном случае на бурятском, русскоязычными школьниками и студентами. Отвечая требованиям времени, словарь был доработан и издан в варианте, который имел 17 переизданий. Это Бурятско-русский и русскобурятский словарь, последнее переиздание которого состоялось в 2019 г.

В известной степени такой спрос на данный словарь объясняется принятием в Республике Бурятия закона о двух государственных языках, введением в русских школах и других ученых заведениях городов и поселков республики и национальных (Усть-Ордынского и Агинского) округов бурятского языка как учебного предмета. Он также используется в национальной бурятской школе при изучении русского языка. 
М. Б. Матанцеева. Практическая лексикография как одно из направлений работы кафедры русского языка и общего языкознания

Словарь включает наиболее частотную лексику и предназначен для широкого круга пользователей с разной языковой подготовкой: учащихся, студентов, всех, кто изучает бурятский или русский как функционально второй язык. Читателю предлагаются переводы основных значений широкоупотребительных слов русского и бурятского языков Автор отмечает во введении, что без такого рода пособий невозможны полноценная работа по переводу с одного языка на второй, составление текстов на неродном языке.

Начиная с последнего десятилетия XX в. в лексикографии происходит обновление традиционных понятий и представлений, и область этих исследований интенсивно расширяется. Создаются словари нового типа, которые помогают будущему «оживлению» лексикографии [Алексеева, 2011, с. 270-278]. Понимание к концу ХХ в. лексикографии как теории и практики составления словарей позволяет выделять теоретическую и практическую лексикографию. К теоретической лексикографии, согласно общепринятому мнению, принято относить теорию и историю лексикографии, к практической - создание словарей и других произведений словарного типа, а также накопление и хранение словарных материалов [Морковкин, 1987, с. 41 ].

Исследователи отмечают, что бурные дискуссии о статусе лексикографии к началу XXI в. постепенно утратили остроту и «... последние работы по лексикографии основываются на научном статусе лексикографии как общепринятом, сложившемся у нас в стране за последние 10-15 лет» [Табанакова, 2001, с. 16]. Филологи пришли к мысли о настоятельной необходимости отразить в лексикографических трудах сложную и противоречивую картину состояния русского языка, который претерпел значительные изменения в лексике, семантике, сочетаемости, стилистической стратификации. Лексикография в этот период переживает фазу активного развития в самых различных направлениях, что в первую очередь связано с радикальными изменениями в общественно-политическом устройстве России в 90-е гг. прошлого века. Лингвистами была осознана необходимость расширения типов и жанров источников толковых словарей современного русского языка, о чем писали в своих работах К. С. Горбачевич, П. Н. Денисов, Ю. Н. Караулов, Г. Н. Скляревская и другие.

Не является исключением и диалектная лексикография. Именно в этот период было издано более десяти региональных диалектных словарей, явивших собой результат интенсивного научного изучения (примерно с середины XX в.) говоров Урала, Сибири и Дальнего Востока, в числе которых «Словарь говоров старообрядцев (семейских) Забайкалья» (1999). В авторский коллектив под руководством Т. Б. Юмсуновой (тогда старшего научного сотрудника сектора русского языка Института филологии СО РАН) вошли как преподаватели кафедры русского языка (А. П. Майоров, Н. А. Дарбанова, М. Б. Матанцева, И. Ж. Степанова, Е. И. Тынтуева), так и сотрудники Бурятского филиала СО РАН (О. М. Козина).

Как отмечается во введении к словарю, Словарь говоров старообрядцев (семейских) Забайкалья представляет собой первую попытку последовательного систематического лексикографического описания древнейших русских говоров этой группы населения на далекой восточной окраине России со всеми особенностями их лексики и семантическими связями с материнскими говорами XVI-XVIII вв.

Как диалектный словарь СГССЗ включает употребляемую носителями этих говоров лексику, не зафиксированную в словарях русского литературного языка или отмеченную в них пометой обл. Словарь толково-переводной, так как в его задачу входит толкование значений диалектного слова через систему литературного языка. В состав работы вошли диалектные слова, имеющие ряд особенностей в сравнении с лексикой литературного языка. 
Выход словаря был отмечен крупными отечественными лингвистами как заметное явление в диалектной лексикографии Сибири (отзывы А.Ф.Журавлева, Л. И. Куркиной, С. А. Мызникова, Ф. П. Сорокалетова, Т. С. Коготковой, Н. А. Лукьяновой и др.). Ценность изданию, по мнению рецензентов, придает полнота охвата ареала проживания забайкальских старообрядцев в Республике Бурятия и Читинской области (ныне Забайкальский край), так как обследованы практически все места компактного проживания семейских в регионе. Кроме того, тематический спектр материала представляет широкую многоплановую картину: это лексика самых разнообразных сфер трудовой деятельности (полеводство, огородничество, животноводство, птицеводство); лексика плотницкого, столярного, санно-тележного, кедрового, охотничьего, рыболовного и других промыслов; названия жилища, хозяйственных построек, домашней утвари, пищи, одежды, обуви, головных уборов и украшений; лексика природы (растительный и животный мир, ландшафт, метеорологические явления); лексика, характеризующая человека (названия частей тела, физические особенности, характеристика личности, социальные отношения); экспрессивная лексика; широко представлена религиозно-культовая и обрядовая лексика.

К числу достоинств СГССЗ, как свидетельствуют специалисты, относится хороший уровень лингвистической интерпретации слова, качество иллюстративного материала в контекстах, наличие этнографических зарисовок, схем и фотографий в приложении, что сделало Словарь надежным источником для лингвистических, исторических, этнографических исследований. Также высоко было оценено художественное оформление книги, благодаря которому книга получила Большую золотую медаль в номинации «За вклад в развитие книжного дела в Сибири» на ежегодной Сибирской ярмарке «Книга Сибири-2000».

Работа авторского коллектива была высоко оценена и мировой общественностью: именно после выхода Словаря устное творчество и культурное поселение семейских были включены ЮНЕСКО в список российских памятников нематериальной культуры в 2001 г.

Достойным продолжением работы преподавателей кафедры над лексикой говоров семейских стало лексикографическое описание «Экспрессивная лексика говоров старообрядцев Забайкалья», выполненное одним из авторов СГССЗ Н. А. Дарбановой в 2007 г. и представляющее собой опыт аспектного словаря.

Источником материала данного издания послужили записи диалектной речи, осуществленные автором во время диалектологических экспедиций, а также большой фактический материал, собранный в полевых условиях студентами и преподавателями, и не вошедший до этого в СГССЗ.

Следует отметить, что экспрессивная лексика долгое время оставалась за пределами внимания исследователей, однако ситуация изменилась. Интерес к изучению экспрессивной лексики русских говоров обусловлен практикой составления диалектных словарей, когда перед исследователями возникла необходимость в лексикографической интерпретации экспрессивных лексических единиц: в описании их семантики, их свойств, в выявлении отношений, в которые они вступают, и т. п. Значительные достижения в области исследований экспрессивной лексики, ведущихся в системно-семантическом, прагматическом, когнитивном, сравнительносопоставительном и других аспектах, а также продолжающаяся работа по сбору, систематизации и описанию такой лексики способствует появлению словарей экспрессивной лексики и фразеологии.

Данное издание является опытом Словаря экспрессивной лексики говоров семейских Забайкалья, над полным вариантом которого автор работает. Словарь явля- 
М. Б. Матанцеева. Практическая лексикография как одно из направлений работы кафедры русского языка и общего языкознания

ется диалектным толковым системным аспектным словарем дифференциального типа. В словарь включены собственно диалектные, а также диалектно-просторечные экспрессивные лексические единицы, так как экспрессивная лексика русских говоров имеет интердиалектный характер и располагается на стыке диалектной и просторечной подсистем.

Следующая работа стала одним из успешных результатов многолетней работы научного направления кафедры «Региональный вариант национального языка Забайкалья: история и современное состояние», которым руководит автор труда проф. А. П. Майоров. Это региональный исторический «Словарь русского языка XVIII в.: Восточная Сибирь. Забайкалье» (2011), ставший, по мнению рецензентов, «...естественным звеном в цельном блоке тематически связанных публикаций автора (Памятники забайкальской деловой письменности XVIII века. Улан-Удэ, 2005; Очерки лексики региональной деловой письменности XVIII в., М., 2006)».

Данный словарь представляет собой авторский лексикографический труд, посвященный варианту русского языка 18-го столетия, функционировавшего в регионах, прилежащих к озеру Байкал (современные территории Иркутской и Читинской областей, Республики Бурятия и Республики Саха-Якутия). В словаре использован уникальный материал рукописных памятников деловой письменности из собраний государственных архивов Иркутской и Читинской областей, Национального архива Республики Бурятия и Российского государственного архива древних актов.

Словарь содержит лексику, характеризующую региональный вариант национального языка восемнадцатого столетия. В него включены книжно-славянские слова той эпохи, заимствования из европейских языков и, самое главное, регионализмы вторичные диалектизмы северорусского происхождения и заимствования из языков коренного населения Восточной Сибири и Дальнего Востока, выделяющие разговорный идиом Забайкалья того времени среди других форм общенародного языка. Словарь в первую очередь предназначен для специалистов - лингвистов, историков, этнографов, но, безусловно, интересен всем, кто увлечен историей русского языка.

По мнению специалистов по истории языка, словарь представляет собой значимое явление в региональной лексикографии (Л. А. Глинкина, И. А. Малышева, М. Э. Рут). Собранные и описанные в словаре лексемы детально отражают специфику региона и быт его населения, разнообразные явления местной экономической, церковной и частной жизни. Это многочисленные наименования животных и их мастей, одежды и тканей, растений, жилищ, хозяйственных построек, средств передвижения, ремесленная и строительная терминология, названия посуды, кушаний, напитков и многое другое.

Особую ценность в словаре представляет разговорная лексика (общеупотребительная и региональная), а также устойчивые словосочетания и фразеологизмы, в том числе региональные идиомы. Большинство вошедших в словарь лексем введено в научный оборот впервые, поскольку лексический состав архивных рукописей, использованных в качестве источников, ранее не исследовался. В этом заключается важная и неоспоримая заслуга автора. Всего описано около 8000 лексических единиц, соответствующий словник помещен отдельно. Приложение содержит репродукции рукописей, изобразительные материалы, фотографии.

В настоящее время лексикографическая деятельность кафедры русского языка и общего языкознания сохраняет традиционную активность. В числе проектов работа по составлению краткого словообразовательного словаря бурятского языка (руководитель Д. Ш. Харанутова). 
На современном этапе, с внедрением компьютерных технологий, в рамках теоретической и практической лексикографии наметились инновационные тенденции: стали интенсивно развиваться такие новые разделы, как корпусная лексикография и кибернетическая лексикография. Неумолимые тенденции лексикографии XXI в., ориентированной на пользователя и обучаемого, а не на лексикографа и непосредственно словарь, требуют включения в процесс. В числе ближайших задач кафедры видится создание источников - электронных банков аутентичных языковых данных, которые предоставляют неограниченные возможности для изучения языка [Карпова, 2000, с. 63-72]. Решению этой проблемы посвящена деятельность научного направления кафедры Региональные варианты национального языка: история и современное состояние (руководители А. П. Майоров, Д. Ш. Харанутова). Начальные звенья этой цепи уже существуют в виде хрестоматии «Русская разговорная речь Бурятии: тексты в орфографической записи» (сост. А. П. Майоров, И. Ж. Степанова).

\section{Лuтература}

1. Алексеева Л. М. Словарь без границ // Ивановская лексикографическая школа: традиции и инновации. Иваново: Изд-во ИвГУ, 2011. С. 270-278. Текст: непосредственный.

2. Бабушкин С. М. Бурятско-русский и русско-бурятский словарь. Улан-Удэ: Изд-во Бурят. гос. ун-та, 2000. 447 с. Текст: непосредственный.

3. Дарбанова Н. А. Лексикографическое описание экспрессивной лексики говоров старообрядцев Забайкалья. Улан-Удэ: Изд-во Бурят. гос. ун-та, 2007. 222 с. Текст: непосредственный.

4. Денисов П. Н. Лексика русского языка и принципы ее описания. Москва: Русский язык, 1980. 253 с. Текст: непосредственный.

5. Карпова О. М. Новые тенденции в современной лексикографии // Лексика и лексикография: сборник научных трудов. Москва, 2000. Вып. 11. С. 63-72. Текст: непосредственный.

6. Морковкин В. В. Об объеме и содержании понятия «теоретическая лексикография» // Вопросы языкознания. 1987. № 6. С. 45-61. Текст: непосредственный.

7. Морковкин В. В. Основы теории учебной лексикографии: диссертация на соискание ученой степени доктора филологических наук в форме научного доклада. Москва, 1990. 72 с. Текст: непосредственный.

8. Русский язык. Энциклопедия / главный редактор Ю. Н. Караулов. 2-е изд., перераб. и доп. Москва, 1997. 703 с. Текст: непосредственный.

9. Словарь говоров старообрядцев (семейских) Забайкалья. Новосибирск: Изд-во СО РАН, 1999. 540 с. Текст: непосредственный.

10. Словарь русского языка XVIII в: Восточная Сибирь. Забайкалье / А. П. Майоров. Москва: Азбуковник, 2011. 583 с. Текст: непосредственный.

11. Табанакова В. Д. Идеографическое описание научной терминологии в специальных словарях: диссертация на соискание ученой степени доктора филологических наук. Тюмень, 2001. 288 с. Текст: непосредственный.

Статья поступила в редакцию 19.09.2021; одобрена после рецензирования 15.10.2021; принята к публикации 29.10.2021. 
М. Б. Матанцеева. Практическая лексикография как одно из направлений работы кафедры русского языка и общего языкознания

\title{
PRACTICAL LEXICOGRAPHY AS ONE OF THE AREAS OF WORK OF RUSSIAN LANGUAGE AND GENERAL LINGUISTICS DEPARTMENT
}

\author{
Marina B. Matantseva \\ Cand. Sci. (Phil.), A/Prof. of Russian Language and General Linguistics Department, \\ Dorzhi Banzarov Buryat State University \\ 6 Ranzhurova St., Ulan-Ude 670000, Russia \\ m_matantseva@mail.ru
}

\begin{abstract}
The Dictionary of Dialects of Transbaikal Old Believers' (Semeiskie)". The All-Russian Conference "Issues of Regional, Modern and Historical Lexicography and Lexicology", held by Russian Language and General Linguistics Department of Dorzhi Banzarov Buryat State University, is timed to this event. The article presents an overview of the main lexicographic works of the lecturers of this department. Among them are "Buryat-Russian and Russian-Buryat Dictionary", "The Dictionary of Dialects of Transbaikal Old Believers (Semeiskie)", the lexicographic description of "The Expressive Vocabulary of Dialects of Transbaikal Old Believers", "The Russian Dictionary of the $18^{\text {th }}$ Century: Eastern Siberia. Transbaikalia" - works that have become a noticeable phenomenon in the regional and Siberian lexicography. We also emphasized new objectives and prospects of lexicographic work.

Keywords: practical lexicography, anniversary of the dictionary, lexicographic works, translation bilingual dictionary, dialect dictionary, regional historical dictionary, aspect dictionary, expressive vocabulary dictionary, dictionary projects, chrestomathy.
\end{abstract}

\section{For citation}

Matantseva M. B. Practical Lexicography as One of the Areas of Work of Russian Language and General Linguistics Department. Bulletin of Buryat State University. Philology. 2021; 3: 65-71 (In Russ.).

The article was submitted 19.09.2021; approved after reviewing 15.10.2021; accepted for publication 29.10.2021. 